\title{
La importancia de la palabra en los orígenes de la filosofía griega
}

\author{
ORLANDO BELTRÁN MORENO*
}

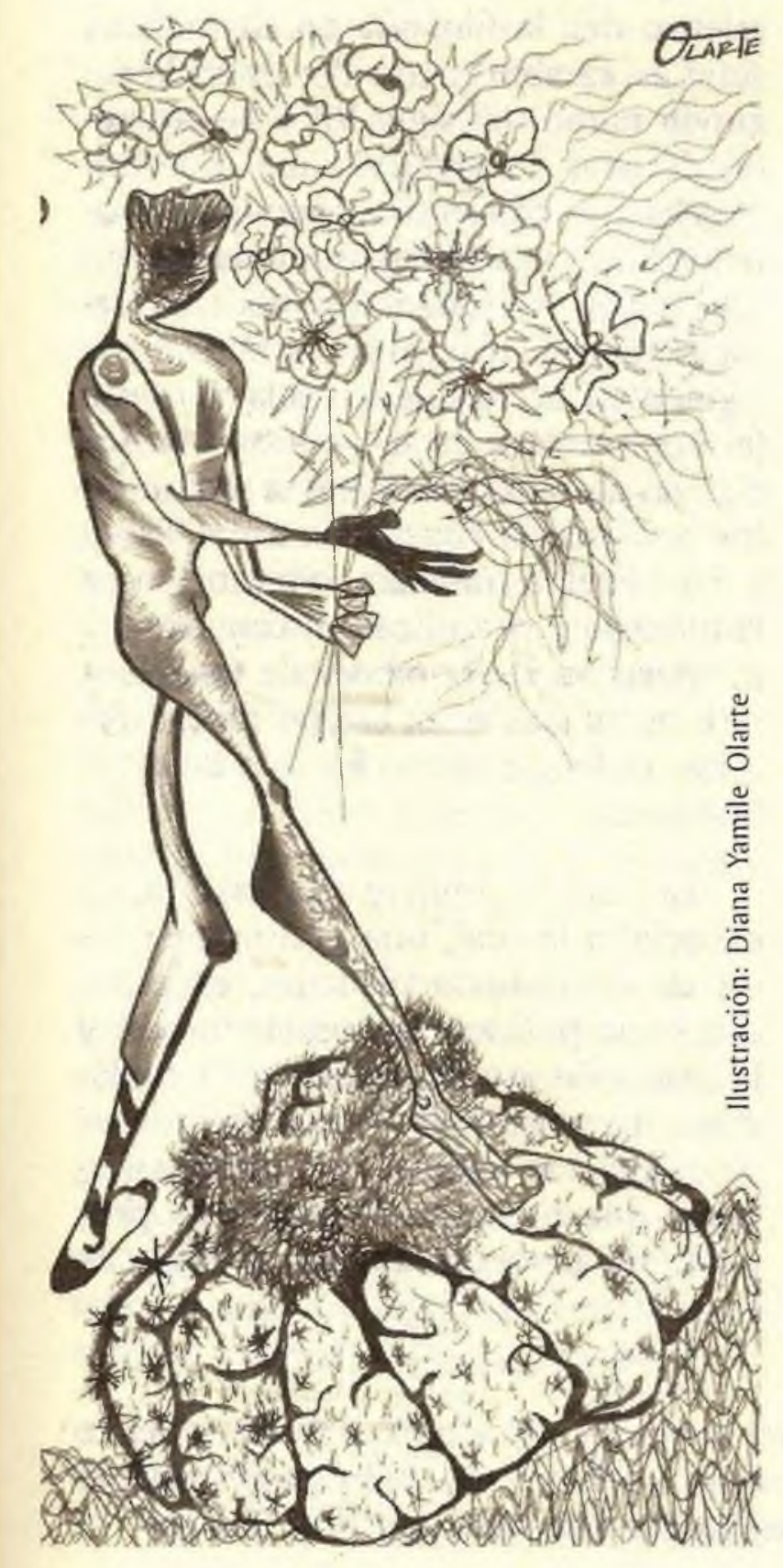

nn el siglo VI a.n.e. en la Grecia an4 tigua tres hombres ilustrados de Lla polis de Mileto, Tales, Anaximandro y Anaxímenes, quienes son considerados por la tradición filosófica occidental como los primeros filósofos, empiezan a construir explicaciones racionales del origen del mundo, de su composición y de su ordenamiento por fuera de las creencias míticas y religiosas, para ellos todo lo que existe es physis; es por medio del logos que se puede captar e interpretar el mundo como physis. A partir de Tales de Mileto la naturaleza se contempla y analiza de acuerdo a sus leyes inmanentes y a un principio material, sin la intervención de las potencialidades divinas; con esta posición cognoscitiva de Tales se inaugura una nueva manera de interpretar y de expresar las cosas, de pensar el mundo como totalidad, que será denominada después Filosofía.

Para expresar la autonomía e independencia que tienen los seres vivientes, los fenómenos naturales y Los objetos del poder de los dioses, los filósofos de Mileto introducen las "formas

* Filósofo de la Universidad Nacional. 
neutras" en el lenguaje griego y un nuevo vocabulario. Con el nacimiento de la filosofía la palabra se limita a designar las cosas, deja de pretender identificarse con la realidad como sucedía en los relatos míticos y religiosos de creación del mundo. La palabra en este tipo de mitos teogónicos y cosmogónicos es característica de éstos debido a que ella no se reduce solo a designar las cosas, sino que tiene la creencia de identificarse con las mismas cosas que nombra'. Los individuos que se encuentran inmersos en esta clase de mitos creen firmemente que el nombre y la realidad nombrada se encuentran supeditados a una relación directa y necesaria. En varios mitos de creación del mundo se suele creer que conocer el nombre de una realidad implica conocer su esencia. Lo anterior permite entender que en el conocimiento mítico saber el nombre de una cosa o de un ser viviente suponga poder ingresar en su campo propio de realidad, en su identidad, y desde ahí, tener la posibilidad de hacerla suya, de dominarla y de controlarla mágicamente.

En el estudio del nacimiento de la filosofía no se puede olvidar que éste acontecimiento se encuentra estrechamente relacionado con la fundación y constitución de las ciudades-Estados (poleis) griegas, aproximadamente hacia el 800 a.n.e., este fue un acontecimiento revolucionario en la historia de los griegos dado que cambió notablemente su manera de vivir, sus relaciones sociales, políticas económicas y su visión de mundo.
El proceso de laicización y de racionalización que genera el establecimiento de las ciudades-Estados griegas, conjuntamente con la libertad de pensamiento y de palabra, de intercambio de conocimientos, de prosperidad económica, la ausencia de doctrinas sagradas incuestionables, de una Iglesia poderosa, de monarquías absolutas son factores que favorecieron el advenimiento de la filosofía, a principios del siglo VI a.n.e., en las tierras griegas del Asia Menor. También contribuyeron al nacimiento de la filosofía en Grecia una serie de cambios ocurridos entre la segunda mitad del siglo VII y las primeras décadas del siglo VI a.n.e., que evidencian una creciente autonomía y creatividad de las actividades humanas con relación a los esquemas y modelos tradicionales, estos cambios fueron los siguientes: la búsqueda de la eunomía (el buen orden) en la política y lo social, la creación de la fuerza militar de los hoplitas, la constitución del Tribunal del Pueblo (Helieae), la invención de la moneda y su utilización comercial, y la aparición de hombres de invenciones ingeniosas en el campo de las técnicas (Tales de Mileto fue uno de estos hombres).

La polis le confiere a la palabra, en especial a la oral, una gran importancia en todas sus actividades, en especial en la política, la argumentación y la discusión arraigan en la vida ciudadana. La palabra empieza a reconocerse como una valiosa herramienta humana que tiene sus limitaciones propias, sin poderes divinos y mágicos

1. Este hecho se puede constatar, por ejemplo, en narraciones míticas como el Poema babilónico de la Creación (Enuma Elis), la Teogonía de Hesiodo, el "Primer relato de la Creación" del libro del Génesisy en el Prólogo del Evangelio según San Juan de la Biblia. 
ínsitos, también deja de aceptarse que la palabra de ciertos seres humanos, como la de los reyes, sea extraordinaria, poseedora de la verdad y del saber $y$, por ende, incuestionable. En la polis la palabra se torna en un recurso clave para los ciudadanos, saberla emplear de forma correcta y con destreza en los momentos adecuados hace factible que se tenga éxito en lo que se persigue; se toma conciencia que la palabra es muy importante para persuadir, argumentar, discutir, litigar, negociar, etc.. La práctica de las discusiones, en especial las que ocurrían en reuniones privadas y con participantes calificados y en un mismo plano de igualdad, contribuyeron también a la formación del pensamiento racional entre los griegos gracias a la calidad y la profundidad que éstas alcanzaban. En dichas discusiones las argumentaciones de los interlocutores se construían de forma consistente, lógica e inteligente, como se puede apreciar, por ejemplo, en los diálogos socráticos de Platón, la victoria en este agón dialéctico lo obtenía quien presentaba mejores argumentos y era más lógico; aquí triunfaba no el que tenía más poder, ni más recursos económicos ni más fuerza física sino el que sabía hablar de manera convincente y exponer bien sus argumentos.

Todos los asuntos que sean de interés para la polis y sus ciudadanos se discuten y resuelven a través de un debate oratorio en el ágora, es decir, en la plaza pública que ocupa un lugar central en su espacio urbano, es aquí donde suele cobrar más importancia la palabra por ser un lugar de reunión para realizar diversas actividades básicas de los ciudadanos. La desaparición del sistema monárquico y palatino de las tierras griegas hizo que el poder dejase de ser propiedad absoluta de una persona, el Rey, quien presumía de tener ascendencia divina, y que el Estado se despojara de todo carácter privado y personal, para tornarse en un campo que era de interés de todos los ciudadanos. En la polis la palabra se vuelve el recurso político más apreciado para persuadir acerca de la conveniencia o validez de diversas medidas de gobierno o de políticas, para ejercer la autoridad y el poder que otorgan los ciudadanos, para fiscalizar el desempeño de quienes gobiernan, para discutir y para litigar. La razón griega se forja en buena parte en la actividad política; es en el empleo de la palabra, en el estudio de las técnicas que permiten actuar e influir sobre los seres humanos y de las reglas de la demostración de las proposiciones, donde la razón griega se ha formado primeramente ${ }^{2}$. Todo esto es una consecuencia del establecimiento y constitución de la polis entre los griegos.

El surgimiento de la filosofía en la Grecia antigua desencadenó una transformación mental en el hombre griego que ocasionó cambios en su pensamiento mítico y religioso en el cual transcurría su existencia. Los primeros filósofos llevan a cabo una ruptura con la lógica de la ambivalencia en la que se basaba el mito, a través de ésta la mente percibía un mismo fenómeno como un hecho natural en el mundo visible y a la vez como un hecho divino en el mundo mítico y religioso. Los elementos naturales a los cuales se refieren los 
filósofos milesios en sus interpretaciones de la realidad no son potencias divinas como Gea, Urano y Océano, son simples principios físicos, se limitan a ser solo la tierra, el agua, el fuego y el aire. Los pensadores de Mileto determinan bien a los elementos naturales y conciben de manera abstracta sus propiedades físicas particulares. A juicio de jean Pierre Vernant las cualidades abstractas de los elementos son subs-

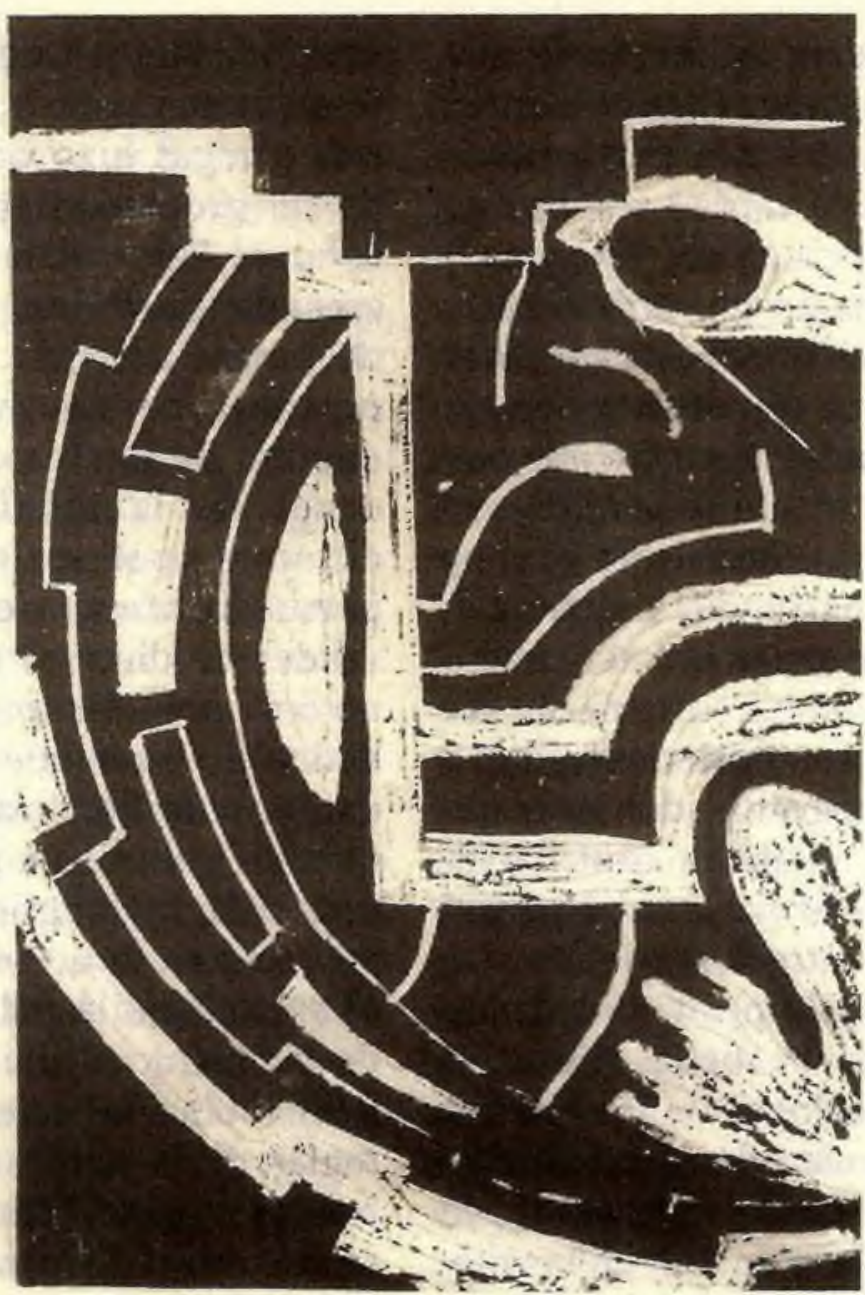

Ilustración: Diana Yamile Olarte

milesios empiezan a diferenciar los diversos planos que conforman la realidad para evitar confundirlos y no incurrir en la ambigüedad como le acontecía al mito, gracias a ello se establece la separación del plano natural, del plano humano y del plano divino, cum-pliéndose de esta manera con un requisito básico para el buen ejercicio del pensamiento racional.

En la contantivadas y objetivadas por los filósofos milesios mediante el empleo novedoso del artículo determinado griego tó ${ }^{3}$ : lo terroso, lo húmedo, lo caliente y lo seco; cada elemento produce un efecto físico preciso que se puede expresar con los términos neutros del lenguaje griego. Los filósofos de Mileto se atreven así a pensar y vivir en el interior de un mundo que se explica por su coherencia causal interna, por las relaciones que tienen las cosas entre sí, y no por la intervención de los dioses. Los pensadores

cepción filosófica de Tales de Mileto, a quien se considera el primer investigador de la naturaleza de las cosas como un todo y a quien se tiene en la tradición filosófica occidental como el primer filósofo griego, la totalidad de lo existente es physis. El término physis significa que todas las cosas son procesos de nacimiento y crecimiento a partir de los elementos materiales que las componen, estos procesos obedecen a un impulso inmanente y constante. Para Tales de Mileto el elemento y prin-

3. J.P. Vernant. Mito y pensamiento en la Grecia antigua. Barcelona. Editorial Ariel. 1983. Ps. 341.342 . 
PAIDEIA

cipio generatriz de todas las cosas es físico: el agua (hydor) ${ }^{4}$, él no habla del dios Océano. Tales de Mileto piensa que todo el universo procede del agua, que debido a cambios y evoluciones sucesivas da lugar a las múltiples cosas que constituyen el universo. A partir de Tales de Mileto los fenómenos naturales son interpretados y analizados conforme a una casualidad Física, originada y dirigida por el principio material que se estima los informa y anima; las cosas se observan ahora tal cual son, los fenómenos sólo pertenecen a su estado natural de relaciones físicas. La manera de pensar de Tales de Mileto modifica sustancialmente las relaciones entre el hombre y las cosas, haciendo factible un nuevo tipo de enfoque, de situación, desde la cual la racionalidad trabaja de acuerdo a otras exigencias de comprensión; el ser humano se ubica ante las cosas en otras condiciones de inteligibilidad.

El mundo es leído ahora con los filósofos milesios de acuerdo a la lógica interna de las cosas, a sus leyes y a sus diversas clases de relaciones, y no según la voluntad y los mandamientos de los dioses, los cuales los filósofos hacen a un lado por considerarlos propios de otra dimensión o plano, los cuales respetan con actitud crítica. Los pensadores milesios no creen que todas las cosas dependan de los dioses, ni que ellos sean su principio explicativo. La physis absorve ahora la dignidad y la primordialidad que anteriormente tenían de manera exclusiva los poderes divinos. Este cambio va acompañado de otro que tiene lugar en los propios hombres ilustrados griegos, quienes se sitúan en y ante las cosas en una posición de neutralidad, esta nueva actitud de los filósofos milesios frente a las cosas se evidencia en las modificaciones que experimenta el lenguaje griego. Es así como los milesios introducen las "formas neutras" en el lenguaje griego y crean nuevas palabras para expresar la autonomía e independencia que tienen los fenómenos físicos de los seres divinos. Estas innovaciones linguiísticas griegas hicieron posible a los hombres griegos abordar a los fenómenos y las fuerzas naturales no como si fuesen seres míticos o divinos sino como simples cosas "neutras" y "autonomas"; de esta forma las imágenes antropomórficas del mundo, características de las concepciones míticas y religiosas, son sustituidas en la filosofía de los milesios por un lenguaje de corte abstracto y neutro. Los filósofos milesios logran que la naturaleza comience a "neutralizarse" en sus significados que ella encierra con el empleo de este lenguaje abstracto y neutro, los fenómenos naturales dejan de verse de manera personificada, mágica y sagrada.

La lectura que se afectúa ahora de la realidad se fundamenta en el $\log _{0} s^{5}$, es a través de él que se la interpreta y se expresa en el discurso como physis.

4. Véase Aristóteles. Metafísica de Aristóteles. Madrid. Editorial Gredos. 1982. A 3, 983 b 627; Diógenes Laercio. Vida de los más ilustres filósofos griegos. Vol. 1. Barcelona. Ediciones Orbis. 1986. Tales. 5 p.27

5. Es conveniente y clarificador precisar aquí el sentido en que se emplea el término logos, para este menester me remito a la reflexión que sobre él hace el estudioso español de la 
El logos da cuenta de la realidad tal como esta es, con argumentos que pueden probarse y están abiertos a la discusión y la crítica. Mientras el discurso del logos tiene la pretensión de ser verdad demostrable, el discurso del mythos (mito) no demuestra lo que dice, no aporta pruebas, ni se somete a la discusión crítica.

Con el nacimiento de la filosofía la palabra deja de identificarse con la realidad como ocurría en las teogonías y las cosmogonías, ahora se limita a nombrar las cosas. Los objetos a los cuales se refieren los nombres se encuentran en el discurso filosófico claramente separados, el nombre pierde la carga afectiva y emotiva que tenía para los hombres en el mito y se vuelve abstracto, neutro y convencional; el nombre ya no pretende contener lo que expresa ni ser un saber de sí mismo sino de otro que se halla exterior a él. El nombre se aparta de lo nombrado y puede tener varios significados a la vez, que en cada circunstancia se deben precisar, se reconoce así la polisemia de las palabras. Los hombres griegos pueden con el surgimiento de la filosofía distanciarse de las entidades físicas y reconocerles una objetividad de manera independiente de su sensibilidad y de su experiencia subjetiva.

Las creencias míticas y religiosas no se extinguieron en la Grecia antigua en el siglo VI a.n.e. con la aparición de la filosofía, ni hubo una ruptura radical con ellas, continuaron teniendo vigencia pero compitiendo ahora con el pensamiento racional y abstracto. Si bien es cierto que existe una nueva manera de comprender las cosas y de situarse en el mundo por parte de los filósofos milesios, no se puede desconocer la influencia que en los comienzos de la filosofía ejercen las antiguas cosmogonías míticas griegas, como la de Hesiodo con su obra la Teogoníat, pues en ellas también se había tratado, a su manera, de explicarse el comienzo y las causas del mundo y de la vida humana. La manera de comprender mítica y religiosa pierde su monopolio interpretativo de la realidad al surgir y arraigar la filosofía en tierras griegas, se plantea ahora entre éstas diferencias de entender el mundo $\mathrm{y}$, también de estar en él, una competencia por imponer su palabra y su concepción de las cosas. La lucha entre el mito y la filosofía no siempre va a ser radical ni de negación absoluta del mito, pues entre ellos en

filosofia griega José Lorite Mena: "Logos tiene como raíz légo, re-coger, es decir, coger con selección y conservar lo que se ha tomado para intercambiarlo con los demás por medio de la palabra. Recoger, pues, seleccionando -lo cual quiere decir que se sabe lo que se busca-; y lo que se busca con el Logos es el mundo como physis. El logos es la cesta, la red, que permite reunir y transportar la visión del mundo como physis a la palabra para ofrecerlo a los demás; el logos es la nueva moneda de cambio del lenguaje- es el nuevo recorrido y la nueva posición del espectador. Así podemos comprender que para $\mathrm{M}$. Heidegger la significisión fundamental del logos es inseparable de la physis. "Teoría y técnica de los origenes de la filosofía." En A partir de los griegos. Bogotá. Universidad de Los Andes. 1983. P. 46.

6. Véase Olof Gigón. Los orígenes de la filosofía griega. Madrid. Editorial Gredos. 1971. Ps.13-44. 
Paidela

ocasiones se ha dado cierta "colaboración". Las creencias míticas y religiosas tradicionales siguieron teniendo sentido e importancia para los griegos en el siglo Vl a.n.e. y en los siglos siguientes continuaron siendo provechosas para la consolidación de su cultura. La filosofía griega no excluyó al mito de su campo, algunos filósofos, como Platón, tuvieron cierta conciencia de su sentido y valor y llegaron a utilizarlo en el tratamiento y exposición de temáticas complejas. En otras ocasiones las interpretaciones filosóficas se han tornado míticas con su vana pretensión de querer apresar y explicar toda la realidad en sus sistemas de pensamiento.

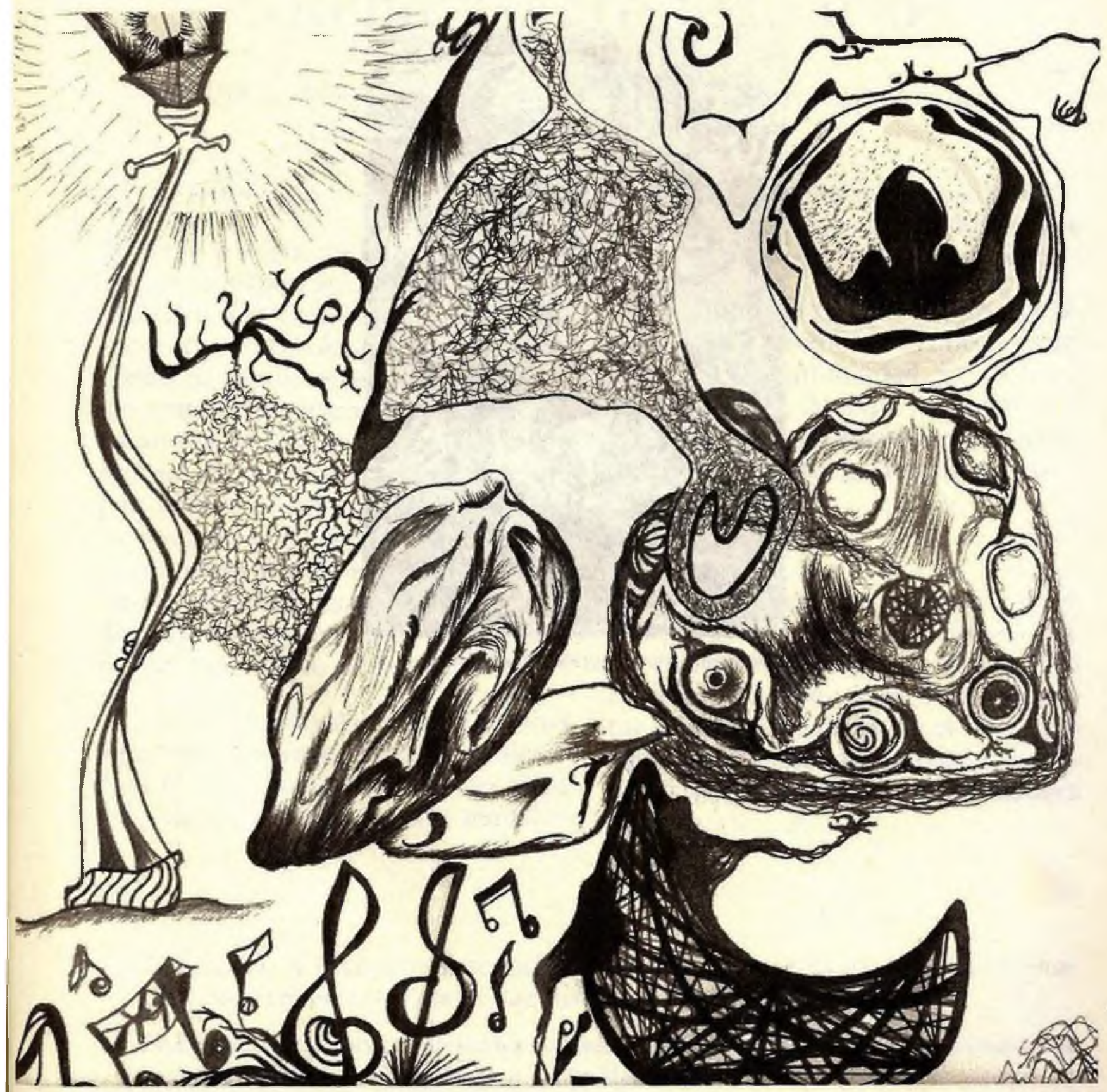

Hustración: Diana Yamile Olarte 


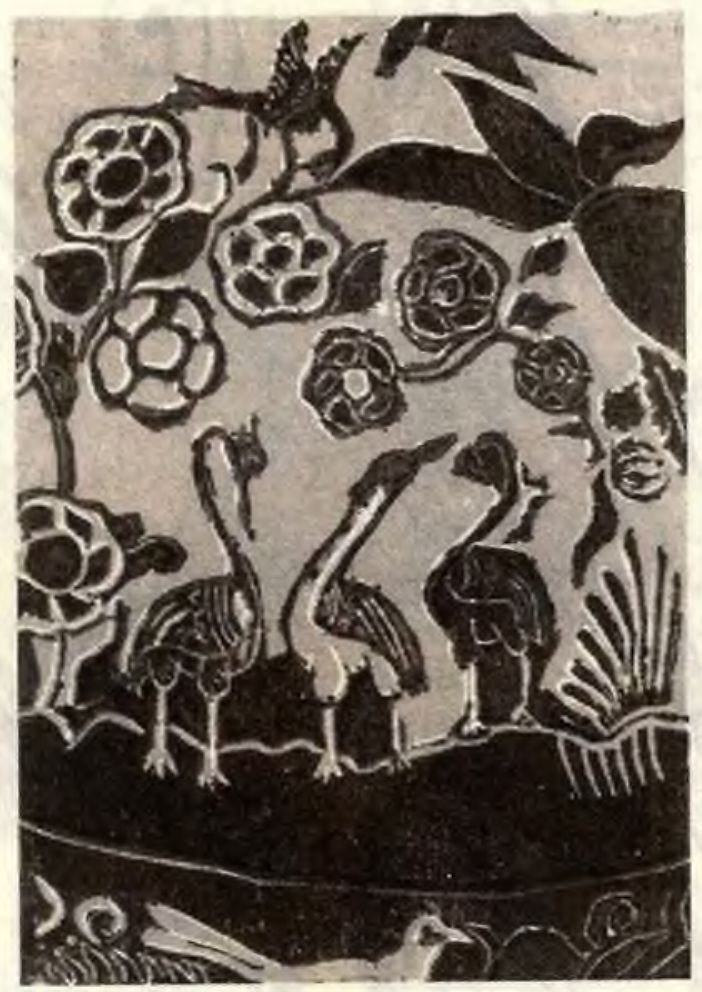

Ilustración: Marco Aurelio Mendez S. 